\title{
Desenvolvimento e caracterização de doce e geleia de abacaxi 'pérola' com flor de camomila desidratada e canela em pau
}

No presente estudo objetivou-se elaborar produtos artesanais (doce em massa e geleia) e avaliar as características físico-químicas e sensoriais dos produtos saborizados com flor de camomila e canela em pau produzidos a partir dos frutos de abacaxi Pérola. Foi realizada caracterização física de 100 amostras de frutos através das medidas de peso dos frutos (PF), peso da polpa (PP), peso da casca (PC), peso da coroa (PCA), avaliação do diâmetro, comprimento dos frutos e rendimento da polpa. Para a caracterização físico-química da polpa, do albedo e dos produtos artesanais elaborados foram realizadas as análises de $\mathrm{pH}$, acidez total titulável, sólidos solúveis totais, umidade, cinzas, teor de proteínas totais, lipídios, carboidratos e o valor energético total. Os resultados obtidos das análises físico-químicas e sensoriais foram realizados pelo teste de Tukey a $5 \%$ de probabilidade. Em relação à caracterização física dos frutos de abacaxi Pérola, os parâmetros avaliados como comprimento $(31,05 \mathrm{~cm})$, diâmetro $(14,86 \mathrm{~cm})$ caracterizam os frutos no formato cônico. Quanto aos valores obtidos para o peso médio dos frutos $(1.350,50 \mathrm{~kg})$, e rendimento da polpa $(53,33 \%)$ estão acima dos valores relatados na literatura. Os teores médios de $\mathrm{pH}$, ${ }^{\circ} \mathrm{Brix}$, umidade, cinzas, carboidratos e valor energético total para a polpa de abacaxi estão próximos aos estipulados pela Tabela Brasileira de Composição de Alimentos - TACO e ANVISA De acordo com os resultados obtidos, os produtos podem se tornar uma opção de aproveitamento integral dos frutos de abacaxi, logo uma forma alternativa de renda para o pequeno produtor da região do Sudeste do Parà.

Palavras-chave: Analises Físico-Químicas; Matérias-Primas; Agricultura Familiar.

\section{Development and characterization of 'pearl' pineapple jam and jam with dehydrated chamomile flower and cinnamon stick}

\begin{abstract}
The objective of this study was to elaborate artisanal products (sweet and jelly) and to evaluate the physicochemical and sensorial characteristics of the products flavored with chamomile and cinnamon sticks produced from the Pérola pineapple fruits. It was performed a physical characterization of 100 fruit samples through fruit weight (PF), pulp weight (PP), bark weight (PC), crown weight (PCA), diameter, fruit length and yield of the pulp. For the physicochemical characterization of the pulp, albedo and elaborated artisanal products, $\mathrm{pH}$, total titratable acidity, total soluble solids, moisture, ashes, total protein content, lipids, carbohydrates and total energy value were performed. The results obtained from the physicochemical and sensorial analysis were performed by the Tukey test at $5 \%$ probability. Regarding the physical characterization of the pear pineapple fruits, the parameters evaluated as length $(31.05 \mathrm{~cm})$, diameter $(14.86 \mathrm{~cm})$, characterize the fruits in the conical format. The values obtained for the average fruit weight $(1.350,50 \mathrm{~g})$ and pulp yield $(53.33 \%)$ are above the values reported in the literature. The average levels of $\mathrm{pH},{ }^{\circ} \mathrm{Brix}$, moisture, ashes, carbohydrates and total energy value for pineapple pulp, which are close to those stipulated by the Brazilian Food Composition Table - TACO and ANVISA. According to the results obtained, the products can become an option for the full utilization of the pineapple fruits, thus an alternative form of income for the small producer of the Southeast region of Pará.
\end{abstract}

Keywords: Physicochemical Analysis; Raw Materials; Family Farming.

Topic: Experimentação Agrícola

Reviewed anonymously in the process of blind peer
Received: 02/03/2020

Approved: 18/04/2020
Juliana Guimarães Rocha (iD) Universidade Federal Rural da Amazônia, Brasil

http://lattes.cnpq.br/1583032465194487 http://orcid.org/0000-0003-1786-5687 juguimaraes95@gmail.com

\section{Rodrigo Cruz Silva (iD)}

Universidade Federal Rural da Amazônia, Brasil

http://lattes.cnpq.br/2232035266243824 http://orcid.org/0000-0003-4946-8387 rodriigocruz@hotmail.com

Luana da Silva Pinheiro Universidade Federal Rural da Amazônia, Brasil

http://lattes.cnpq.br/8813568000316450 luulupinheiro@hotmail.com
João Paixão dos Santos Neto Instituto Nacional de Investigação Agrária Veterinária, Brasil http://lattes.cnpq.br/2828947517814190 joaopaixaoneto@gmail.com

Antônio Thiago Madeira Beirão (D) Universidade Federal Rural da Amazônia, Brasil http://lattes.cnpq.br/89490068888604428 http://orcid.org/0000-0003-1366-5995 thiago.ppgee.ufpa@gmail.com

\section{Katiane Pereira da Silva (iD)}

Universidade Federal Rural da Amazônia, Brasil http://lattes.cnpq.br/3810443896855581 http://orcid.org/0000-0002-1697-6804 katianeperei@gmail.com

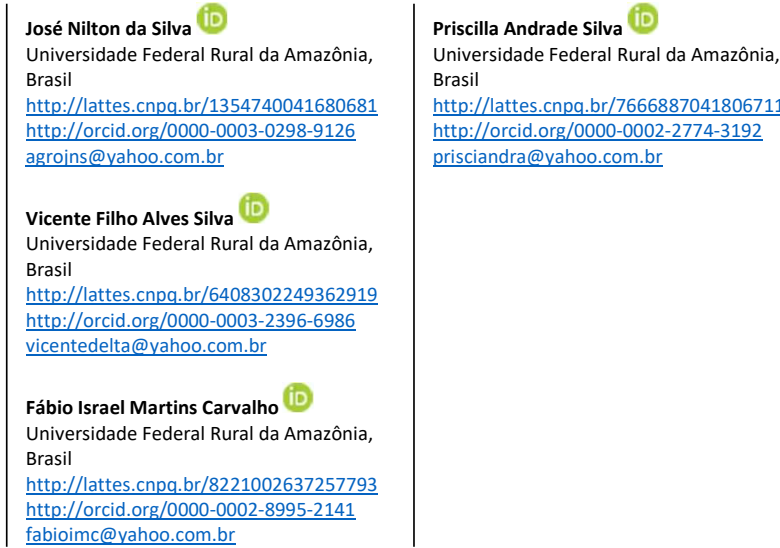

José Nilton da Silva (iD

http://lattes.cnpq.br/1354740041680681 http://orcid org/0000-0003-0298-9126 agrojns@yahoo.com.br Universidade Federal Rural da Amazônia, http://orcid.org/0000-0003-2396-6986 vicentedelta@yahoo.com.br

Israel Martins Carvalho Universidade Federal Rural da Amazônia, fabioimc@yahoo.com.br
Referencing this:

ROCHA, J. G.; SILVA, R. C.; PINHEIRO, L. S.; SANTOS NETO, J. P.; BEIRÃO, A. T. M.; SILVA, K. P.; SILVA, J. N.; SILVA, V. F. A.; CARVALHO, F. I. M.; SILVA, P. A.. Desenvolvimento e caracterização de doce e geleia de abacaxi 'pérola' com flor de camomila desidratada e canela em pau. Revista Ibero Americana de Ciências Ambientais, v.11, n.3, p.44-59, 2020. DOI: http://doi.org/10.6008/CBPC21796858.2020 .003 .0005 


\section{INTRODUÇÃO}

O abacaxizeiro (Ananas comosus L., Merrill) é uma das frutíferas tropicais mais cultivadas no mundo. Em 2018, o Brasil produziu 1.766.986 ton., com área de cultivo de 71.553 há (IBGE, 2019) e ocupa o segundo maior produtor de abacaxi, sendo responsável por $12 \%$ de toda a produção mundial. As regiões Norte e Nordeste se destacam na produção do fruto no país (FAOSTAT, 2018). O abacaxi é considerado um fruto não climatérico, precisa de ser colhido no estádio de maturação para garantir uma qualidade comestível, muito apreciado pelo seu aroma, sabor e por ser refrescante, além das suas propriedades nutricionais (LOBO et al., 2017).

A cultivar 'Pérola' é muito apreciada no mercado interno brasileiro pela à sua polpa ser suculenta e saborosa, considerada insuperável para o consumo ao natural, fazendo com que os frutos tenham grande potencial de comercialização internacional, pois também são muito apreciados no Mercosul e na Europa (SOUTO et al., 2004).

A composição química do abacaxi varia de acordo com a época do ano em que é produzido, variedade e condições climáticas (GRANADA et al., 2004). A qualidade dos frutos de abacaxizeiro é atribuída às suas características físicas externas (coloração da casca, tamanho e forma do fruto) e internas conferidas por ampla faixa de constituintes, apresenta quantidade considerável de potássio, ferro, cálcio, manganês e magnésio (SOARES et al., 2004). Os frutos de melhor qualidade têm alto conteúdo de açúcar (SST) e baixa acidez titulável (ATT), esta razão é o parâmetro que mais se relaciona à palatabilidade e, consequentemente, à aceitação dos frutos pelo consumidor (FREIMAN et al., 1999).

Atualmente tem buscado novos meios de aproveitamento da fruta, por ser muito perecível, assim a agroindústria desempenha o papel de produzir polpas, sorvetes, iogurtes, doces, geleias e entre outros produtos, fazendo com que tenha no mercado uma diversidade de opções para o consumidor (COSTA et al., 2013). Com o intuito de apresentar uma nova alternativa de fonte de renda para o produtor de abacaxi da região sudeste do Pará, através da elaboração e caracterização de produtos artesanais, foram formulados os seguintes produtos: (i) doce de massa e (ii) geleia.

O doce em massa é obtido através do cozimento das frutas adicionando-se o açúcar até atingir a consistência desejada, pode ser pastoso ou em massa de tal forma que possibilite o corte. Além do açúcar, outros ingredientes podem vir a ser acrescentados como a pectina e o ácido cítrico, que contribuem para a boa liga do doce. A fabricação é simples e eficiente na conservação de frutas, o que torna o doce muito apreciado pelos consumidores e eleva sua comercialização (SILVA, 1997).

A Agência Nacional de Vigilância Sanitária, por meio da Resolução da Diretoria Colegiada, RDC no 272, de 2005, fixou a identidade e as características mínimas de qualidade dos produtos de frutas, o doce em massa se enquadra como partes comestíveis das frutas adicionados de açúcares, água, pectina $(0,5$ a 1,5\%) e pH (3 a 3,4), dentre outros ingredientes e aditivos permitidos pela legislação brasileira, até alcançar consistência adequada (ANVISA, 2005).

A geleia é um produto de umidade intermediária preparada com polpa de frutas, açúcar, pectina, 
ácido e outros ingredientes, que permitem sua conservação por um período prolongado (BASU et al., 2013). A pectina empregada na elaboração de geleias tradicionais deve apresentar alto teor de metoxilação (ATM). Javanmard et al. (2012) referem-se que o mecanismo de geleificação da pectina ATM é por interações hidrófobas e pontes de hidrogênio em condições ácidas $(\mathrm{pH}<3,4)$ e baixa atividade de água (cerca de $55 \%$ de açúcar), o que a torna apropriada para ser utilizada em geleias.

De acordo com RDC № 272, de 2005, define que as geleias podem ser classificadas segundo percentual da fruta ou de seus ingredientes como, comum e extra. A comum, a proporção mínima de 40 partes de frutas para 60 partes de açúcar, enquanto a extra, proporção mínima de 40 partes de frutas para 60 partes de açúcar. Diante o exposto, objetivou-se com o presente estudo realizar primeiramente a caracterização biométrica dos frutos, análises físico-químicas da polpa de abacaxi e do albedo de maracujá, seguido da elaboração de doce em massa e geleia e posterior caracterização físico-química dos mesmos.

\section{METODOLOGIA}

\section{Material}

Os frutos de abacaxi cultivar Pérola foram coletados na propriedade rural Sítio Moreira localizada em Floresta do Araguaia, com as seguintes coordenadas geográficas: $07^{\circ} 31^{\prime} 23^{\prime \prime}$ de latitude Sul e $47^{\circ} 39^{\prime} 04$, 9" de longitude a Oeste colhidos aos 18 meses após plantio. Para a elaboração dos produtos (doce em massa e geleia) foram utilizadas as seguintes matérias-primas: polpa de abacaxi, albedo de maracujá extraído dos frutos (Passiflora edulis), açúcar refinado, flor de camomila desidratada e canela em pau, comercializados nos supermercados de Parauapebas/PA.

\section{Métodos}

Os produtos elaborados, doce em massa e geleia de abacaxi foram desenvolvidos na Universidade Federal Rural da Amazônia, no campus de Parauapebas Pará, localizada nas coordenadas geodésicas $49^{\circ} 51^{\prime} 19^{\prime \prime}$ W latitude, $06^{\circ} 12^{\prime} 58^{\prime \prime}$ S longitude, com altitude de 197m com auxílio do GPS portátil (Modelo eTrex 10, Marca Garmin), assim como todas as análises físicas, físico-químicas. O período de realização do trabalho foi de março a julho de 2018. Para as formulações de doce em massa e geleia de abacaxi adequadas, foram realizados vários testes com diferentes concentrações de cada matéria-prima empregada.

\section{Caracterização física dos frutos e rendimento das polpas}

Após a coleta dos frutos, foi realizada uma amostra aleatória contendo 100 frutos para a caracterização física. Este procedimento consistiu na determinação das medidas de peso dos frutos (PF), peso da polpa (PP), peso da casca (PC), peso da coroa (PCA) e avaliação do diâmetro e comprimento dos frutos, com auxílio de paquímetro metálico $300 \mathrm{~mm}$ (Marca Vonder) com precisão de 0,01 mm.

O rendimento da polpa de abacaxi foi realizado pela separação da polpa, casca e coroa manualmente e os rendimentos foram determinados através de suas respectivas massas, com auxílio de balança semi- 
analítica (Modelo ARD110, Marca OHAUS Adventurer).

\section{Processo de obtenção das polpas de abacaxi e do albedo de maracujá}

Os frutos selecionados foram lavados, sanitizados por imersão em solução com hipoclorito de sódio (200 mg/L) durante 15 minutos e novamente imersos em água por 15 minutos, separadamente. Em seguida, as amostras dos frutos foram manualmente separadas da polpa, batidas em liquidificador, peneiradas e embaladas em sacos plásticos de polietileno de $1 \mathrm{Kg}$ e congeladas a $-20^{\circ} \mathrm{C}$ para serem utilizada nas análises físico-químicas e no processamento dos produtos artesanais.

No processo de obtenção do albedo, os maracujás foram cortados com faca de aço inoxidável e as sementes e suco foram separados do albedo (parte branca da casca do maracujá), com auxílio de uma colher. O albedo foi retirado da película amarela (flavedo) do maracujá com auxílio de uma faca de aço-inox, submetendo ao processo de fervura (aproximadamente 20 minutos) por imersão em água, na proporção de $500 \mathrm{~g}$ de albedo e $1 \mathrm{~L}$ de água. Após a drenagem da água e o resfriamento, o albedo foi submetido ao processo de trituração em liquidificador, acrescido de água mineral na proporção de 1:1. Em seguida o gel foi envasado em recipientes de vidro de $250 \mathrm{ml}$ e armazenadas sob refrigeração a $8^{\circ} \mathrm{C}$ até o momento da formulação das geleias e dos doces em massa.

\section{Processamento dos produtos artesanais de abacaxi com camomila e canela}

Para as formulações dos doces em massa (F1=30\% de polpa de fruta com partícula; 35\% de açúcar; 15\% de xarope de glicose; $20 \%$ de albedo de maracujá; F2: $30 \%$ de polpa de fruta com partícula; $35 \%$ de açúcar; $15 \%$ de xarope de glicose; $19,95 \%$ de albedo de maracujá; 0,05\% de flor de camomila desidratada e F3: $30 \%$ de polpa de fruta com partícula; 35\% de açúcar; $15 \%$ de xarope de glicose; $19,9 \%$ de albedo de maracujá; $0,1 \%$ de canela em pau), as polpas concentradas e com partículas foram acrescidas em função do teor de sólidos solúveis, segundo o cálculo, a quantidade de açúcar suficiente para elevar a $70^{\circ}$ Brix por balanço de massa (Equação 1): $\mathrm{Mp} \times{ }^{\circ} \mathrm{Brixp}+\mathrm{Ma} \times{ }^{\circ}$ Brixa $=$ Mproduto $\mathrm{x}^{\circ}$ Brixproduto, onde: $\mathrm{Mp}=$ massa de polpa; ${ }^{\circ}$ Brixp $={ }^{\circ}$ Brix da polpa; Ma $=$ massa de açúcar; ${ }^{\circ} B r i x a={ }^{\circ}$ Brix do açúcar; $M p=$ massa do produto (geleia ou doce em massa); ${ }^{\circ}$ Brixp= massa do produto. Em seguida, apenas a polpa e as especiarias foram pasteurizadas $\left(90^{\circ} \mathrm{C}\right.$ por 30 segundos), e demais ingredientes foram acrescentados sob aquecimento ( $\mathrm{T}<$ $\left.100^{\circ} \mathrm{C}\right)$ até atingir o ponto de geleificação $\left(70^{\circ} \mathrm{Brix}\right)$. Os doces foram envasados imediatamente após cocção e mantidos sob temperatura ambiente até o momento das análises físico-químicas.

As formulações de geleias (F1= 30\% de polpa de fruta sem partícula; 35\% de açúcar; $15 \%$ de xarope de glicose; $20 \%$ de albedo de maracujá; F2: $30 \%$ de polpa de fruta sem partícula: $35 \%$ de açúcar; $15 \%$ de xarope de glicose; 19,95\% de albedo de maracujá; 0,05\% de flor de camomila desidratada e F3: 30\% de polpa de fruta sem partícula; 35\% de açúcar; $15 \%$ de xarope de glicose; $19,9 \%$ de albedo de maracujá; 0,1\% de canela em pau). Foram preparadas de maneira semelhante as dos doces em massa, com distinção apenas para o teor de sólidos solúveis, ajustado para $65^{\circ}$ Brix, seguido da etapa de filtração das partículas sólidas 
após a pasteurização. Foi calculado a quantidade de sacarose suficiente para elevar o teor de sólidos solúveis dos produtos elaborados: doce em massa e geleia, 70 e $65^{\circ}$ Brix respectivamente, utilizando-se o cálculo de balanço de massa, de acordo com a equação 1.

\section{Caracterização físico-químicas das matérias-primas e dos produtos artesanais de abacaxi}

As seguintes análises foram realizadas em triplicata $(n=3)$ na polpa de abacaxi e no albedo de maracujá, assim como nos produtos artesanais elaborados: pH: determinado em potenciômetro (Marca Hanna Instruments, Modelo HI9321), de acordo com o método 981.12 da AOAC (1997); Acidez total titulável (ATT): realizada por titulometria com solução de hidróxido de sódio $0,1 \mathrm{~N}$ até a primeira coloração rosa persistente por aproximadamente 30 segundos, e fator de conversão do ácido cítrico foi de 64,02 (AOAC, 1997); Sólidos solúveis totais (SST): foram quantificados nas amostras, segundo AOAC (1997); Umidade: determinada por gravimetria, em estufa (Marca Tecnal, Modelo TE - 395), de acordo com o método 920.151 da AOAC (1997); Cinzas: as amostras foram incineradas em forno tipo mufla a $550^{\circ} \mathrm{C}$, de acordo com o método 930.05 da AOAC (1997); Proteínas: foram determinadas em um espectrofotômetro do tipo UVVisível (Marca Bioespectro, Modelo SP-220) de acordo com Método do Biureto descrito por Layne (1957); Lipídios: determinado através da extração com mistura de solventes a frio, método de Bligh et al. (1959); Carboidratos: foi calculado por diferença, segundo Resolução n 360 de 23 de dezembro de 2003 (ANVISA, 2003). Carboidratos (\%): [100 - (\% umidade + \% proteína + \% lipídios + \% cinzas)]; Valor energético total (VET): foi estimado (kcal/100g) utilizando-se os fatores de conversão de Atwater: $4 \mathrm{kcal} / \mathrm{g}$ para carboidratos e proteínas e $9 \mathrm{kcal} / \mathrm{g}$ para lipídios segundo Anderson et al. (1988) e a Resolução $\mathrm{n}^{\circ} 360$ de 23 de dezembro de 2003 (ANVISA, 2003).

\section{Análise estatística}

Os resultados das análises físicas dos frutos, físico-química da polpa e do albedo de maracujá foram analisados por estatística descritiva se utilizando medidas de tendência central (média) e de variabilidade de dados (desvio-padrão). Já, os resultados das análises físico-químicas dos produtos artesanais de abacaxi com camomila e canela elaborados foram avaliados através das médias submetidas à análise de variância, e as médias comparadas pelo Teste de Tukey a 5\% de probabilidade, utilizando-se o software SAS ${ }^{\circledR}$ versão 9.4 (SAS INSTITUTE, 2013).

\section{RESULTADOS}

\section{Caracterização física dos frutos e rendimento das polpas}

Os valores médios obtidos nas determinações dos parâmetros físicos e rendimento dos frutos de abacaxi pérola podem ser visualizados na Tabela 1. 
Tabela 1: Caracterização física unitária e rendimento médio dos frutos de abacaxi.

\begin{tabular}{|c|c|c|}
\hline Determinações físicas & Frutos & \\
\hline Comprimento $(\mathrm{cm})$ & $31,05 \pm 2,68$ & \\
\hline Diâmetro $(\mathrm{cm})$ & $14,86 \pm 0,22$ & \\
\hline Coroa $(\mathrm{cm})$ & $9,62 \pm 1,60$ & \\
\hline Sem coroa $(\mathrm{cm})$ & $21,43 \pm 2,08$ & \\
\hline Peso dos frutos (g) & $1350,50 \pm 208,75$ & \\
\hline Peso das cascas e coroa (g) & $546,77 \pm 116,27$ & \\
\hline Peso da polpa (g) & $720,27 \pm 103,13$ & \\
\hline Rendimento & Peso dos Frutos (Kg) & Peso dos Frutos (\%) \\
\hline Frutos com casca (Kg.frutos) & 135,050 & 100,00 \\
\hline Frutos sem casca (Kg.frutos) & 80,637 & 59,71 \\
\hline Casca dos Frutos e coroa (Kg.frutos) & 54,677 & 40,49 \\
\hline Polpas (Kg.frutos) & 72,027 & 53,33 \\
\hline
\end{tabular}

Análise estatística descritiva, os valores representam a média \pm desvio padrão de 100 amostras.

\section{Caracterização físico-química das matérias-primas}

Os parâmetros das matérias-primas utilizadas, polpa de abacaxi e albedo do maracujá, na elaboração dos produtos estão dispostos na Tabela 2.

Tabela 2: Caracterização físico-química das matérias-primas.

\begin{tabular}{|l|l|l|}
\hline \multirow{2}{*}{ Determinações } & \multicolumn{2}{c|}{ Molpa de abacaxi } \\
\cline { 2 - 3 } & \multicolumn{1}{|c|}{ Albedo do maracujá } \\
\hline $\mathrm{pH}$ & $3,70 \pm 0,01$ & $5,78 \pm 0,10$ \\
\hline $\mathrm{SST}\left({ }^{\circ} \mathrm{Brix}\right)^{* *}$ & $11,03 \pm 0,07$ & $1,17 \pm 0,28$ \\
\hline $\mathrm{ATT}(\mathrm{g} / 100 \mathrm{~g})^{* *}$ & $1,25 \pm 0,01$ & $0,13 \pm 0,00$ \\
\hline Umidade $(\mathrm{g} / 100 \mathrm{~g})$ & $89,36 \pm 0,32$ & $98,07 \pm 0,29$ \\
\hline Cinzas $(\mathrm{g} / 100 \mathrm{~g})^{* *}$ & $0,43 \pm 0,07$ & $0,15 \pm 0,05$ \\
\hline Lipídios $(\mathrm{g} / 100 \mathrm{~g})^{* *}$ & $0,66 \pm 0,03$ & $0,34 \pm 0,05$ \\
\hline Proteínas $(\mathrm{g} / 100 \mathrm{~g})^{* *}$ & $0,32 \pm 0,01$ & $0,24 \pm 0,02$ \\
\hline Carboidratos $(\mathrm{g} / 100 \mathrm{~g})^{* *}$ & $9,23 \pm 0,31$ & $1,14 \pm 0,25$ \\
\hline VET $(\mathrm{Kcal} / 100 \mathrm{~g})$ & 44,14 & 8,58 \\
\hline
\end{tabular}

${ }^{* *}$ Resultados em base úmida. SST - Sólidos Solúveis Totais; ATT - Acidez Total Titulável; VET - Valor Energético Total.

\section{Caracterização físico-química dos produtos elaborados}

Os valores médios obtidos para os parâmetros avaliados, acidez total titulável (ATT), umidade, e carboidratos não diferiram ( $p>0,05$ ) entre as três formulações de doce em massa (Tabela 3). Para os teores cinzas, lipídios e proteínas foram maiores nos doces Doce em massa de abacaxi com camomila - DMCN ( $<<$ 0,05), e também o teor de sólidos solúveis totais (SST) e pH no Doce em massa de abacaxi - DM $(p<0,05)$ (Tabela 3).

Tabela 3: Caracterização físico-química dos doces em massa de abacaxi.

\begin{tabular}{|l|l|l|l|l|l|l|}
\hline \multirow{2}{*}{ Parâmetros } & \multicolumn{5}{c|}{ Doce em massa de abacaxi } \\
\cline { 2 - 7 } & \multicolumn{1}{|c|}{ DM } & \multicolumn{1}{|c|}{ DMCM } & \multicolumn{1}{c|}{ DMCN } & \multicolumn{1}{c|}{ DMS } & \multicolumn{1}{c|}{ F calc. } & \multicolumn{1}{c|}{ CV } \\
\hline pH & $3,72 \pm 0,02^{\mathrm{b}}$ & $3,81 \pm 0,01^{\mathrm{a}}$ & $3,76 \pm 0,01^{\mathrm{b}}$ & 0,0457 & 21,23 & 0,49 \\
\hline TSS ( ${ }^{\circ}$ Brix) & $76,83 \pm 0,76^{\mathrm{a}}$ & $75,16 \pm 0,28^{\mathrm{b}}$ & $75,16 \pm 0,28^{\mathrm{b}}$ & 1,2526 & 11,11 & 0,67 \\
\hline ATT (g/100g) & $0,78 \pm 0,06^{\mathrm{a}}$ & $0,92 \pm 0,06^{\mathrm{a}}$ & $0,86 \pm 0,01^{\mathrm{a}}$ & 0,1390 & 4,57 & 6,49 \\
\hline Umidade (g/100g) & $28,03 \pm 0,63^{\mathrm{a}}$ & $28,06 \pm 0,15^{\mathrm{a}}$ & $38,97 \pm 0,59^{\mathrm{a}}$ & 24,993 & 1,14 & 31,28 \\
\hline Cinzas (g/100g) & $0,20 \pm 0,05^{\mathrm{ab}}$ & $0,10 \pm 0,05^{\mathrm{b}}$ & $0,23 \pm 0,03^{\mathrm{a}}$ & 0,1266 & 5,27 & 27,91 \\
\hline Lipídios (g/100g) & $0,68 \pm 0,08^{\mathrm{b}}$ & $0,19 \pm 0,01$ & $0,84 \pm 0,03^{\mathrm{a}}$ & 0,1283 & 128,76 & 8,93 \\
\hline Proteínas (g/100g) & $0,60 \pm 0,03^{\mathrm{b}}$ & $0,68 \pm 0,01^{\mathrm{ab}}$ & $0,69 \pm 0,05^{\mathrm{a}}$ & 0,0831 & 5,65 & 5,05 \\
\hline Carboidratos (g/100g) & $70,48 \pm 0,75^{\mathrm{a}}$ & $70,35 \pm 0,22^{\mathrm{a}}$ & $59,26 \pm 0,62^{\mathrm{a}}$ & 25,057 & 1,24 & 14,99 \\
\hline VET (Kcal/100g) & 290,44 & 285,83 & 247,36 & & & \\
\hline
\end{tabular}

DMS - Diferença mínima significativa; médias seguidas pela mesma letra na mesma linha não diferem estatisticamente entre si pelo teste de Tukey ao nível de $5 \%$ de probabilidade; ns - não significativo; ${ }^{*}$ - significativo ao nível de $5 \%$ de probabilidade. ${ }^{* *}$ Resultados em base úmida. VET - Valor Energético Total. DM (Doce em massa de abacaxi); DMCM (Doce em massa de abacaxi com camomila); DMCN (Doce em massa com canela). 
Tabela 4: Caracterização físico-química das geleias de abacaxi.

\begin{tabular}{|c|c|c|c|c|c|c|}
\hline \multirow[t]{2}{*}{ Parâmetros } & \multicolumn{6}{|c|}{ Geleia de Abacaxi } \\
\hline & GA & GACM & GACN & $D M S$ & F calc. & $C V$ \\
\hline $\mathrm{pH}$ & $3,25 \pm 0,01^{c}$ & $3,40 \pm 0,01^{a}$ & $3,31 \pm 0,01^{b}$ & 0,0312 & 114,50 & 0,38 \\
\hline TSS ( ${ }^{\circ}$ Brix) & $74,67 \pm 0,57^{b}$ & $77,67 \pm 0,58^{a}$ & $72,17 \pm 0,29^{c}$ & 1,2526 & 91,00 & 0,67 \\
\hline ATT (g/100g) & $0,89 \pm 0,01^{\mathrm{a}}$ & $0,83 \pm 0,07^{a}$ & $0,87 \pm 0,01^{a}$ & 0,0888 & 2,10 & 4,10 \\
\hline Umidade $(\mathrm{g} / 100 \mathrm{~g})$ & $30,62 \pm 1,08^{a}$ & $30,57 \pm 1,48^{a}$ & $32,59 \pm 3,70^{a}$ & 5,9956 & 0,70 & 7,66 \\
\hline Cinzas (g/100g) & $0,23 \pm 0,03^{a}$ & $0,26 \pm 0,02^{\mathrm{a}}$ & $0,26 \pm 0,04^{a}$ & 0,0868 & 0,75 & 13,86 \\
\hline Lipídios (g/100g) & $0,21 \pm 0,02^{b}$ & $0,27 \pm 0,01^{b}$ & $0,73 \pm 0,05^{a}$ & 0,0843 & 208,51 & 8,32 \\
\hline Proteínas $(\mathrm{g} / 100 \mathrm{~g})$ & $0,40 \pm 0,12^{\mathrm{a}}$ & $0,39 \pm 0,01^{\mathrm{a}}$ & $0,36 \pm 0,01^{\mathrm{a}}$ & 0,1768 & 0,22 & 18,35 \\
\hline Carboidratos (g/100g) & $68,54 \pm 0,91^{a}$ & $68,51 \pm 1,45^{a}$ & $66,06 \pm 3,75^{a}$ & 5,98 & 1,07 & 3,52 \\
\hline VET (Kcal/100g) & 277,65 & 278,03 & 272,25 & & & \\
\hline
\end{tabular}

DMS - Diferença mínima significativa; médias seguidas pela mesma letra na mesma linha não diferem estatisticamente entre si pelo teste de Tukey ao nível de $5 \%$ de probabilidade; ns - não significativo; ${ }^{*}$ - significativo ao nível de $5 \%$ de probabilidade. ${ }^{* *}$ Resultados em base úmida. VET - Valor Energético Total. GA (Geleia de abacaxi); GACM (Geleia de abacaxi com camomila); GACN (Geleia de abacaxi com canela).

\section{DISCUSSÃO}

Os valores das características físicas, comprimento e diâmetro indicam o formato cônico. Os resultados deste estudo corroboram com Pereira et al. (2009) que observaram os parâmetros físicos de abacaxis cultivados em Miranorte/TO, para o comprimento médio dos frutos o valor encontrado foi de 35,4 cm, o diâmetro médio dos frutos apresentou $10,4 \mathrm{~cm}$.

A coroa avaliada neste trabalho, Tabela 1, apresentou valor inferior ao de Pedreira et al. (2008) que encontraram 14,1 cm para a referida cultivar nas condições edáficas de Goiânia/GO. Ventura et al. (2009) verificaram o peso médio de frutos de abacaxi de $1.650 \mathrm{~g}$ da variedade 'Pérola' cultivada em Sooretama/ES, valor este superior ao observado no presente estudo (Tabela 1).

Considerando que o rendimento dos frutos de abacaxi 'Pérola' avaliados foi elevado, pode-se afirmar o seu excelente potencial para indústria. Segundo Carvalho et al. (1981), o abacaxizeiro é uma planta, da qual apenas $22,5 \%$ correspondem à polpa do fruto, comestível e altamente industrializada. Dos $77,5 \%$ restantes, a casca contribui com $4,5 \%$ e a parte vegetativa com $73 \%$. Os resíduos da sua industrialização, constituídos por talos, coroas e cascas, podem corresponder em até $40 \%$ do seu peso.

As características físicas dos frutos de abacaxi encontradas no referido trabalho, quando comparadas com os autores supracitados apresentaram diferenças significativas, pois uma possível explicação deve-se as condições edafoclimáticas características da região que esses frutos foram cultivados. Na Tabela 2, os parâmetros das matérias-primas utilizadas na elaboração dos produtos. A polpa de abacaxi obteve pH de 3,70, sendo assim considerado um fruto ácido. Thé et al. (2010) avaliaram as características físico-químicas de abacaxi cv. Smooth cayenne recém colhido obteve $\mathrm{pH}$ em torno de 3,85.

O teor de sólidos solúveis está relacionado com estádio de maturação do fruto, quanto maior ${ }^{\circ}$ Brix mais maduro encontra-se o fruto. A variação do teor de sólidos solúveis em relação aos valores da literatura pode ser explicada pelo genótipo do fruto, assim como, fatores climáticos, solo e irrigação em excesso, os quais podem ocasionar redução dos sólidos solúveis (MACIEL et al., 2016). Com isso, a polpa de abacaxi apresentou um resultado de acordo com a norma vigente, média $11,03{ }^{\circ}$ Brix (Tabela 2 ) e o mínimo estabelecido é $11,0^{\circ} \mathrm{Brix}$, estando de acordo com os padrões de identidade e qualidade para polpa de fruta 
de abacaxi (BRASIL, 2000).

A polpa de abacaxi apresentou valor médio de acidez total titulável de 1,25 g/100g (Tabela 2), considerando que o mínimo estabelecido é de 0,30 g/100g (BRASIL, 2000). Portanto, podemos afirmar que fruto de abacaxi apresentava-se azedo pois apresentou um baixo teor de ${ }^{\circ}$ Brix e alto teor de ATT. Lainetti (2017) encontrou sobre a elaboração de geleia de abacaxi com pimenta um valor médio de 0,46 g/100g de acidez na polpa. Lima et al. (2017) encontraram 0,32g/100g de acidez em seu estudo sobre o aproveitamento agroindustrial de resíduos provenientes do abacaxi pérola minimamente processado. Os ácidos são importantes para o equilíbrio da constituição do flavor, pois influencia a aceitação do produto.

A umidade apresentou um valor médio de 89,36 g/100g (Tabela 2), superior ao encontrado pela Tabela Brasileira de Composição de Alimentos - TACO (2011) de 86 g/100g Lima et al. (2017) observaram um valor de 85,43 g/100g em resíduo de abacaxi pérola. Assim observa-se a alta perecibilidade do fruto e a importância da industrialização dos produtos vegetais.

O teor de cinzas obtido foi de 0,43 g/100g (Tabela 2) superior ao verificado por Bortolatto et al. (2008) $(0,38 \mathrm{~g} / 100 \mathrm{~g})$, afirmam que os teores de cinzas variam em função da localidade onde a variedade foi plantada e da composição do solo onde cresceram os frutos. De acordo com a tabela de composição de alimentos do IBGE (2015), a polpa de abacaxi deve apresentar um valor de no mínimo de 0,30 g/100g cinzas.

Embora o teor de lipídios seja baixo na matéria integral, encontra-se bem estabelecido os seus benefícios pelas diversas funções fisiológicas no organismo humano (COSTA et al., 2008). Na Tabela 2 encontrou-se um teor de 0,66 g/100g, valor este superior ao encontrado por Santos (2017) de 0,30 g/100g em seu trabalho de determinação de micronutrientes em polpas, in natura e industrializada de abacaxi (Ananas Comosus L. Merril) comercializada em São Luís/MA. Emedix (2016) observou um valor de 0,25 $\mathrm{g} / 100 \mathrm{~g}$ de lipídios na composição nutricional do abacaxi.

O teor de proteínas encontrado foi de 0,32 g/100g (Tabela 2), valor inferior encontrado na Tabela de Composição Nutricional dos Alimentos Consumidos no Brasil de 0,54 g/100g (IBGE, 2011). Porém, Santos (2017) observou um valor de 0,35 g/100g, sendo este próximo ao encontrado no estudo. No que se refere ao teor de carboidratos (Tabela 2) na polpa de abacaxi, observou-se um valor de 9,23 g/100g, sendo inferior ao da TACO (2011) que apresenta 12,63 g/100g. Lima et al. (2017) obtiveram um valor médio de 12,46 g/100g para o teor de carboidratos.

Quanto ao valor energético total da polpa de abacaxi se observou um valor médio de 44,14 kcal/100g (Tabela 2). Santos (2017) encontrou valores de 75,66 kcal/100g para polpa in natura de abacaxi pérola e 46,82 kcal/100g para a polpa industrializada; já a TACO (2011) apresenta um valor da ordem de $31 \mathrm{kcal} / 100 \mathrm{~g}$. Pode-se observar na Tabela 2, os valores médios do albedo de maracujá, o qual apresentou um pH de 5,78. Moura et al. (2017) encontraram um valor de pH de 4, 73 para o albedo in natura no estudo sobre a elaboração e caracterização físico-química e sensorial de casca de melão e albedo de maracujá cristalizados.

Em relação ao ${ }^{\circ}$ Brix se obteve um valor de 1,17, Tabela 2. Moura et al. (2017) no estudo verificaram 2,33 ${ }^{\circ}$ Brix para o albedo in natura. Quanto ao parâmetro acidez se observou um valor de 0,13 g/100g. Dias 
et al. (2011) de 0,14 g/100g em avaliaram o aproveitamento do albedo de maracujá na elaboração de doce em massa e alterações com o armazenamento.

A umidade foi de $98,07 \mathrm{~g} / 100 \mathrm{~g}$, Tabela 2. Matsuura (2005) para umidade obteve $90,80 \mathrm{~g} / 100 \mathrm{~g}$ em seu albedo de maracujá. Córdova et al. (2005) encontraram 88,37 g/100g na avaliação das características físico-químicas da casca do maracujá amarelo (Passiflora edulis Flavicarpa Degener) obtida por secagem. A fração cinzas determinada no albedo $(0,15 \mathrm{~g} / 100 \mathrm{~g})$, Tabela 2. Oliveira et al. (2002) verificaram 0,92 g/100 g de cinzas ao avaliarem o aproveitamento alternativo da casca do maracujá-amarelo para produção de doce em calda. Xavier et al. (2015) obtiveram resultado médio de 1,18 g/100g para o teor de cinzas da casca de maracujá obtida a partir dos frutos produzidos pelo setor de fruticultura em Muzambinho-MG.

O valor constatado para proteínas totais no albedo $(0,24 \mathrm{~g} / 100 \mathrm{~g})$, Tabela 2 . Oliveira et al. (2002) foi de 1,07 g/100g para as proteínas totais. Córdova et al. (2005) encontrou valor 0,64 g/100g ao estudarem as características físico-químicas da casca do maracujá amarelo. 0 teor de lipídios de 0,34 g/100g no albedo avaliado (Tabela 2). Rezende et al. (2016) detectaram valores de 0,1 a 1,3 g/100g de lipídios ao analisarem a composição química da casca do maracujá azedo e suas principais características físicas.

Para os carboidratos obtiveram valor médio de 1,14 g/100g. Kogan et al. (2013) apresentaram 6,43 $\mathrm{g} / 100 \mathrm{~g}$ de carboibratos no trabalho sobre o efeito do processamento térmico na composição centesimal do albedo in natura de maracujá amarelo (Passiflora edulis f. Flavicarpa Degener) e da farinha de albedo produzida a $60^{\circ} \mathrm{C}$.

Quanto ao valor energético total do albedo observou-se valor médio de 8,58 kcal/100g (Tabela 2), valor este abaixo do verificado pela TACO (2011) para a polpa de maracujá que estipula um valor médio de $39 \mathrm{kcal} / 100 \mathrm{~g}$. Córdova et al. (2005) encontrou valor calórico de 29,41 kcal/100g em casca de maracujá amarelo, produzido na região de Araquari-SC.

Na tabela 3, as características físico-químicas dos doces em massa de abacaxi. Segundo Gava (2008), o pH de doces de frutas apresentou na ordem de 4,5. As amostras analisadas apresentaram pH de 3,72 a 3,81. Para a formação do gel e obtenção de uma consistência adequada o pH de 3,2 é um valor de referência, uma vez que um pH inferior a 3,2 originará um doce de consistência mais dura e um pH superior uma menor consistência (MAMEDE et al., 2013). Bolzan et al. (2017) demonstraram valores entre 3,58 e 3,70. Almeida et al. (2009), em goiabada notaram um pH de 3,79.

Para os valores de sólidos solúveis ( ${ }^{\circ} \mathrm{Brix}$ ), observou-se os teores de $76,83^{\circ}$ Brix para o doce DM e 75,16 ${ }^{\circ}$ Brix para os doces DMCM e DMCN (Tabela 3). Segundo a Resolução normativa n.ㅇ 9, de 1978 da Agência Nacional de Vigilância Sanitária estabelece que o teor de sólidos solúveis do produto final não deve ser inferior a $65^{\circ}$ Brix para os doces em massa (ANVISA, 1978a). Deste modo, as amostras analisadas se enquadraram dentro deste padrão estabelecido, uma vez que todas obtiveram acima de $70^{\circ}$ Brix (Tabela 3 ). Carvalho et al. (2018) encontraram valores de 76,3 e $81^{\circ}$ Brix ao estudarem sobre a avaliação de qualidade do doce cristalizado de cupuaçu com diferentes dosagens de polpa de camu-camu. Leite Júnior et al. (2013) verificaram em seu doce de manga acrescido de okara valores variando de 61,4 a $70,8{ }^{\circ} \mathrm{Brix}$, durante o 
armazenamento.

Para a acidez total titulável das amostras de doces encontradas de 0,72 a 0,92 g/100g (Tabela 3). Segundo Mamede et al. (2013) valores de acidez entre 0,50 e 0,80 g/100g de ácido cítrico são considerados ótimos, já que valores superiores a 1,00 g/100g causam sinérese (CORREA et al., 2011; MAMEDE et al., 2013) o que corresponde à exsudação do líquido do doce.

Quanto ao teor de umidade, observou-se que a formulação DM (28,03 g/100g) apresentou menor umidade e maior concentração de sólidos solúveis ${ }^{\circ}$ Brix (Tabela 3). Dias et al. (2011) verificaram valores próximos de umidade em doce em massa da casca do maracujá na faixa de 23,77 a 26,91 g/100g. Lima et al. (2017) constataram um teor de umidade máxima 36,81 g/100g em seu trabalho sobre o aproveitamento agroindustrial de resíduos provenientes do abacaxi pérola minimamente processado, valor este próximo a formulação de doce de abacaxi com canela $(38,97 \mathrm{~g} / 100 \mathrm{~g})$.

Para o parâmetro cinzas, os valores encontrados no trabalho foram de 0,10 a 0,23 g/100g (Tabela 3). Freire et al. (2009) obtiveram valores entre 0,29 e 0,33 g/100g na formulação de doce cremoso de goiaba. A menor quantidade de cinzas se deve ao fato do açúcar refinado apresentar um pequeno teor de minerais em sua composição. Santana et al. (2014) no trabalho sobre a qualidade de doce em massa de banana adicionado de componentes funcionais verificaram valores de cinzas que variaram de 0,24 a 0,75 g/100g.

Quanto ao parâmetro lipídios (Tabela 3), as amostras apresentaram valores médios entre 0,19 $\mathrm{g} / 100 \mathrm{~g}$ e $0,84 \mathrm{~g} / 100 \mathrm{~g}$ (DMCN). Orsi et al. (2017) observaram um valor de 0,33 g/100g em doce em massa de feijão azuki (Vigna angularis). Lemke et al. (2016) verificaram um índice de 0,75g/100g de lipídios doce em massa de beterraba (Beta vulgaris L.).

Os valores de proteínas variaram entre 0,60 e 0,69 g/100g (Tabela 3). Miguel et al. (2008) estudaram o aproveitamento agroindustrial de resíduos sólidos provenientes do melão minimamente processado, o mesmo apresentou valores acima de 0,60 g/100g para proteínas. Para doces de manga de acordo com Damiani et al. (2011) apresentaram 1,05 a 1,57 g/100g de proteínas. Os carboidratos exibiram valores entre 59,26 e 70,48 g/100g (Tabela 3). Miguel et al. (2008) no doce em massa de melão por 61,85 g/100g. Lemke et al. (2016) detectaram para os carboidratos 54,70 g/100g no doce em massa de beterraba (Beta vulgaris L.)

O valor energético total do doce em massa de abacaxi (DM) apresentou valor de 290,44 Kcal/100g (Tabela 3), sendo superior ao dos doces com formulações de camomila $(285,83 \mathrm{Kcal} / 100 \mathrm{~g})$ e canela $(247,36$ $\mathrm{Kcal} / 100 \mathrm{~g}$ ). Jacques et al. (2009) encontraram no doce em massa de amora-preta (Rubus spp.) um valor de $243 \mathrm{kcal} / 100 \mathrm{~g}$. Silva et al. (2013) notaram em um valor calórico de 335,85 kcal/100g na Marmelada-decachorro (Alibertia sessilis Schum). Damiani et al. (2011) avaliaram o valor calórico de doces de corte com $100 \%$ de casca de manga e apresentou $285,24 \mathrm{kcal} / 100 \mathrm{~g}$.

Os valores médios obtidos para os parâmetros avaliados, acidez total titulável (ATT), umidade, cinzas, proteínas e carboidratos não diferiram ( $p>0,05$ ) entre as três formulações de geleia (Tabela 4). Os teores de sólidos solúveis totais (SST) e $\mathrm{pH}$ foram maiores na geleia GACM $(p<0,05)$, para o teor de lipídios na geleia 
GACN $(p<0,05)$ (Tabela 4).

Rosa et al. (2011) referem-se que a geleificação acontece mais facilmente na faixa de valores de pH de 3,0 até 3,5. Com valores abaixo de 3,0, ocorre tendência de perda de água da estrutura do gel (MORO et al., 2013). Assim pode-se verificar que os valores das amostras GA $(3,25)$, GACM $(3,40)$ e GACM $(3,31)$ (Tabela 4) estão de acordo com a faixa estimada.

Segundo a ANVISA (1978b), o teor mínimo de sólidos solúveis em geleias deve ser $62^{\circ}$ Brix, entretanto as amostras apresentaram valores acima de 72,17 a 77,67 ${ }^{\circ}$ Brix (Tabela 4). Estes valores altos de sólidos solúveis representam a formação da geleificação durante o cozimento. Licodiedoff et al. (2010) em avaliação da sinérese em geleia de abacaxi por meio de análise uni e multivariada encontraram um valor de 69,70 ${ }^{\circ}$ Brix, já Singh et al. (2009) encontraram 70,5³rix para geleia de abacaxi e mamão.

A acidez é a responsável pela flexibilidade dessa rede formada, sendo que meios menos ácidos tornam essas fibras incapazes de suportar o líquido, impede a formação do gel (GAVA, 2008). Jackix (1988) recomenda que a acidez da geleia não ultrapasse $0,80 \mathrm{~g} / 100 \mathrm{~g}$, assim a acidez encontrada na geleia foi de 0,83 g/100g (GACM) a 0,89 g/100g (GA) (Tabela 4). Querido et al. (2013) em geleia de caqui observaram que variaram entre 0,78 e 0,81g/100g. Moro et al. (2013) conferiram variações de acidez titulável de 0,44 a 0,70 g/100g de ácido cítrico em geleia de uva comercializadas na cidade do Rio Grande/RS.

A faixa estimada pela legislação para umidade varia de 35 a $38 \mathrm{~g} / 100 \mathrm{~g}$ para geleia de frutas de acordo com a resolução $n^{\circ} 12$ da Agência Nacional de Vigilância Sanitária (ANVISA, 1978b). Na Tabela 4 pode-se observar os valores de 30,62 g/100g (GA), 30,57 g/100g (GACM) e 32,59 g/100g (GACN) estão abaixo da legislação. Rosa et al. (2011) encontraram 21,67 g/100g na geleia de abacaxi com hortelã zero açúcar. Caetano et al. (2012) notaram valores de 29,79 a 32,56 g/100g em geleia elaborada com polpa e suco de acerola.

O teor de cinzas representa a substância inorgânica, minerais, presente na amostra. Assim, apresentaram valores entre 0,23 g/100g (GA) e 0,26 g/100g (GACN e GACM). Bolzan et al. (2017) em doce cremoso de caqui com adição de sementes da araucária expuseram um valor de 0,29 g/100g. Vicente et al. (2014) encontram valores de cinzas nas geleias de hibisco orgânicas 0,19 g/100g e na de carambola orgânica $0,16 \mathrm{~g} / 100 \mathrm{~g}$.

Os lipídios são fornecedores de calorias (energia) e de ácidos graxos, substâncias muito importantes para o organismo humano quando consumidas na quantidade certa. E também auxiliam na absorção das vitaminas A, D, E e K (SANTOS, 2011). As geleias de abacaxi apresentaram baixos teores de lipídios nas três formulações GA (0,21 g/100g), GACM (0,27 g/100g) e GACN (0,73 g/100g) dispostos na Tabela 4 . A geleia de murici conforme Monteiro et al. (2015) apresentaram 0,12 g/100g. Yuyama et al. (2008) encontraram 0,38 $\mathrm{g} / 100 \mathrm{~g}$ de lipídios na geleia dietética de cubiu (Solanum sessiliflorum Dunal).

As proteínas devem conter $0,26 \mathrm{~g} / 100 \mathrm{~g}$ segundo a Tabela da USP (2008), as amostras apresentaram valores de 0,36 g/100g (GACN) a 0,40 g/100g (GA) (Tabela 4). Juarez et al. (2014) na geleia de carambola identificaram 0,44 g/100g de proteínas. Cruz (2016) em sua geleia de mamão formosa (Carica papaya) 
encontrou valores de 0,49 a $0,82 \mathrm{~g} / 100 \mathrm{~g}$.

Em se tratando de carboidratos, os valores obtidos no referido estudo foram de $66,06 \mathrm{~g} / 100 \mathrm{~g}$ (GACN), $68,51 \mathrm{~g} / 100 \mathrm{~g}$ (GACM) e 68,54 g/100g (GA), valores próximos comparados com os dados da Tabela da USP (2008) 68,6 g/100g. Oliveira et al. (2014) encontraram um valor de 61,75 g/100g de carboidratos em seu estudo sobre a influência das variáveis de processo nas características físicas e químicas de geleias de umbucajá. Um valor médio de 68,38 g/100g obtido por Scolforo et al. (2013) ao avaliarem a geleia de maçã. Santos et al. (2012) ao avaliarem geleia de cagaita obtiveram $61,76 \mathrm{~g} / 100 \mathrm{~g}$ em seu estudo. 0 valor energético total das amostras apresentou valores de 272,25 Kcal/100g (GACN) e 278,03 Kcal/100g (GACN). Polesi et al. (2011) em geleias de manga expuseram valor médio de $244,04 \mathrm{Kcal} / 100 \mathrm{~g}$. Para as geleias de umbu-cajá, segundo Oliveira et al. (2014) variaram de 229,57 a $247,86 \mathrm{kcal} / 100 \mathrm{~g}$.

\section{CONCLUSÕES}

Com relação a caracterização física dos frutos de abacaxi Pérola, os parâmetros avaliados caracterizam os frutos no formato cônico. Quanto aos valores obtidos para o peso médio dos frutos e rendimento da polpa estão acima dos valores relatados na literatura. 0 rendimento dos frutos avaliados foi elevado, assim o abacaxi Pérola tem um elevado potencial para a agroindustrialização na região que foi cultivado.

Em relação aos parâmetros físico-químicos das matérias-primas, como a polpa de abacaxi e o albedo, observou-se valores médios de $\mathrm{pH},{ }^{\circ} \mathrm{Brix}$, umidade, cinzas, carboidratos e valor energético total para a polpa de abacaxi, que estão próximos de acordo com Tabela Brasileira de Composição de Alimentos - TACO e ANVISA. Quanto ao albedo de maracujá os teores médios de ${ }^{\circ}$ Brix, acidez, cinzas, carboidratos e valor energético total foram inferiores aos encontrados na literatura para a composição do albedo in natura e em cascas de maracujá amarelo, devido a diferentes condições edafoclimáticas de produção. As formulações analisadas de doce em massa e geleia estão de acordo com os padrões físico-químicos do produto que atendem a legislação brasileira, demonstra ser uma alternativa viável para o agricultor familiar.

\section{REFERÊNCIAS}

ALMEIDA, E. L.; RAMOS, A. M.; BINOTI, M. L.; CHAUCA, M. C.; STRINGHETA, P. C.. Análise de perfil de textura e aceitabilidade sensorial de goiabadas desenvolvidas com diferentes edulcorantes. Revista Ceres, Viçosa, v.56, n.6, p.697-704, 2009.

ANDERSON, L.; DIBBLE, M. V.; TURKKI, P. R.; MITCHEL, H. S.; RYNBERGEN, H. J.. Satisfazendo as normas nutricionais. In: Nutrição. 17 ed. Rio de Janeiro: Guanabara, 1988. p.179187.

ANVISA. Agência Nacional de Vigilância Sanitária. Resolução da Diretoria Colegiada - RDC n. 272, de 22 de setembro de 2005. Aprova o regulamento técnico para produtos de vegetais, produtos de frutas e cogumelos comestíveis. Brasília: DUO, 2005.
ANVISA. Agência Nacional de Vigilância Sanitária. Resolução RDC n. 360, de 23 de dezembro de 2003. Aprova o Regulamento Técnico sobre rotulagem nutricional de alimentos embalados. Brasília: DUO, 2003.

ANVISA. Agência Nacional de Vigilância Sanitária. Resolução CNNP n. 9, de 1978. Fixa o Regulamento técnico para fixação dos padrões de identidade e qualidade para doce em massa. Brasília: ANVISA, 1978a.

ANVISA. Agência Nacional de Vigilância Sanitária. Resolução CNNPA n. 12, de 1978. Fixa o Regulamento técnico para fixação dos padrões de identidade e qualidade para geleias. Brasília: ANVISA, 1978b. 
AOAC. Association of Official Analytical Chemists. Official methods of analysis of the Association of Official Analytical Chemists. 16 ed. Washington: AOAC, 1997.

BASU, S.; SHIVHARE, U. S.; SINGH, T. V.. Effect of substitution of stevioside and sucralose on rheological, spectral, color and microstructural characteristics of mango jam. Journal of Food Engineering, Oxford, v.114, n.4, p.465-476, 2013. DOI: http://doi.org/10.1016/j.jfoodeng.2012.08.035

BLIGH, E. C.; DYER, W. J.. A rapid method of total lipid extraction and purification. Canadian Journal Biochemistry Physiology, Ottawa, v.37, p.911-917, 1959. DOI: http://doi.org/10.1139/059-099

BOLZAN, A. B.; PEREIRA, E. A.. Elaboração e caracterização de doce cremoso de caqui com adição de sementes da araucária. Brazilian Journal of Food and Technology, Campinas, v.20, p.e2016061-11, 2017. DOI: http://doi.org/10.1590/1981-6723.6116

BORTOLATTO, J.; LORA, J.. Avaliação da composição centesimal do abacaxi (Ananas comosus (L.) Merril) liofilizado e in natura. Revista de Pesquisa e Extensão em Saúde, v.4, n.1, 2008.

BRASIL. Ministério da Agricultura, Pecuária e Abastecimento. Instrução Normativa n. 01, de 07 de janeiro de 2000. Aprova o Regulamento técnico geral para fixação dos padrões de identidade e qualidade para polpa de fruta. Brasília, 2000.

CAETANO, P. K.; DAIUTO, E. R.; VIEITES, R. L.. Característica físico-química e sensorial de geleia elaborada com polpa e suco de acerola. Brazilian Journal of Food Technology, Campinas, v.15, n.3, p.191-197, 2012. DOI: https://doi.org/10.1590/S1981-67232012005000011

CARVALHO, G. F.; DURIGAN, M. F. M.; LIMA, J. M. T.; GRIGIO, M. L.. Avaliação de qualidade do doce cristalizado de cupuaçu com diferentes dosagens de polpa de camu-camu. In: CONGRESSO SUL BRASILEIRO DE ALIMENTOS, 4; ENCONTRO PARANAENSE DE ENGENHARIA DE ALIMENTOS, 7. Anais. Guarapuava: Unicentro, 2018.

CARVALHO, V. D.; BOTREL, N.. Características da fruta de exportação. In: GORGATTI NETTO, A.. Abacaxi para exportação: procedimentos de colheita e pós-colheita. Brasília: Embrapa, 1996. p.7-15.

CARVALHO, V. D.; CLEMENTE, P. R.. Qualidade, colheita, industrialização e consumo de abacaxi. Informe Agropecuário, Belo Horizonte, v.7, n.74, p.37-42, 1981.

CÓRDOVA, K. R. V.; GAMA, T. M. M. T. B.; WINTER, C. M. G.; KASJANTZIS NETO, G.; FREITAS, R. J. S.. Características físicoquímicas da casca do maracujá amarelo (Passiflora edulis flavicarpa Degener) obtida por secagem. Boletim do Centro de Pesquisa de Processamento de Alimentos, Campinas, v.23, n.2, p.221-230, 2005. DOI: http://dx.doi.org/10.5380/cep.v23i2.4491

CORREA, R. C. G.; SORA, G. T. S.; HAMINIUK, C. I. W.; AMBROSIO-UGRI, M. C. B.; BERGAMASCO, R.; VIEIRA, A. M. S.. Physico-chemical and sensorial evaluation of guava jam made without added sugar. Chemical Engineering
Transactions, Milano, v.24, p.505-510, 2011. DOI:

http://doi.org/10.3303/CET1124085

COSTA, D. O. D.; CARDOSO, G. R.; SILVA, G. M. V. D.. A evolução do setor produtivo e comercialização de polpa de fruta no brejo paraibano: estudo de caso na coaprades. Salvador: ABEPRO, 2013.

COSTA, N. M. B.; PELUZIO, M. C. G.. Nutrição Básica e Metabolismo. Viçosa: UFV, 2008.

CRUZ, V. A.. Desenvolvimento de geleia de mamão formosa (Carica Papaya L.) sob diferentes concentrações e métodos de secagens das sementes. Dissertação (Mestrado em Ciência e Tecnologia em Alimentos) - Instituto Federal de Educação, Ciência e Tecnologia do Triangulo Mineiro, Uberaba, 2016.

DAMIANI, C.; ALMEIDA, A. C. S.; FERREIRA, J.; ASQUIERI, E. R.; VILAS BOAS, E. V.; SILVA, F. A.. Doces de corte formulados com casca de manga. Pesquisa Agropecuária Tropical, Goiânia, v.41, n.3, p.360-369, 2011. DOI: http://doi.org/10.5216/pat.v41i3.9815

DIAS, M. V.; FIGUEIREDO, L. P.; VALENTE, W. A.; FERRUA, F. Q.; PEREIRA, P. A. P.; PEREIRA, A. G. T.; BORGES, S. V.; CLEMENTE, P. R.. Estudo de variáveis de processamento para produção de doce em massa da casca do maracujá (Passiflora edulis f. flavicarpa). Ciência e Tecnologia de Alimentos, Campinas, v.31, n.1, p.65-71, 2011. DOI: https://doi.org/10.1590/S0101-20612011000100008

FAOSTAT. Food and Agriculture Organization of the United Nations Statistical Database. Crops database. FAOSTAT, 2018.

FREIMAN, L. O.; SRUR, A. U. O. S.. Determinação de proteína total e escore de aminoácidos de bromelinas extraídas dos resíduos do abacaxizeiro (Ananas comosus, (L.) Merril). Ciência e Tecnologia de Alimentos, Campinas, v.19, n.2, 1999. DOI: http://doi.org/10.1590/S010120611999000200002

FREIRE, M. T. A.; PETRUS, R. R.; HASHIDA, J. C.; FAVAROTRINDADE, C. S.. Avaliação física, química e sensorial de doce cremoso de goiaba acondicionado em bisnaga plástica. Brazilian Journal of food technology, Campinas, v.12, n.3, p.172-180, 2009. DOI: http://doi.org/10.4260/BJFT2009800900010

GAVA, A. J; SILVA, C. B.; FRIAS, J. R. G.. Tecnologia de alimentos: princípios e aplicações. São Paulo: Nobel, 2008.

GRANADA, G. G.; ZAMBIAZI, R. C.; MENDONÇA, C. R. B.. Abacaxi: produção, mercado e subprodutos. Boletim do Centro de Pesquisa e Processamento de Alimentos, Curitiba, v.22, n.2, p.405-422, 2004. DOI: http://dx.doi.org/10.5380/cep.v22i2.1203

IBGE. Instituto Brasileiro de Geografia e Estatística. Ministério do Planejamento, Orçamento e Gestão. Pesquisa de Orçamentos Familiares 2008/2009: Tabelas de Composição Nutricional dos Alimentos Consumidos no Brasil. Rio de Janeiro: IBGE, 2011. 
IBGE. Instituto Brasileiro de Geografia e Estatística. Sistema IBGE de recuperação automática, SIDRA: levantamento sistemático da produção agrícola. Rio de Janeiro: IBGE, 2019.

IBGE. Instituto Brasileiro de Geografia e Estatística. Tabelas de composição de alimentos. Rio de Janeiro: IBGE, 2015.

JACKIX, M. H.. Doces, geleias e frutas em calda. Campinas: Unicamp, 1988.

JACQUES, A. C.; PERTUZATTI, P. B.; BARCIA, M. T.; ZAMBIAZI, R. C.. Doce em massa de amora-preta (Rubus spp): Analise sensorial e de fitoquímicos. Alimentos e Nutrição, Araraquara, v.20, p.625-631, 2009.

JAVANMARD, M.; CHIN, N. L.; MIRHOSSEINI, S. H.; ENDAN, J. Characteristics of gelling agent substituted fruit jam: studies on the textural, optical, physicochemical and sensory properties. International Journal of Food Science and Technology, Oxford, v.47, n.9 p.1808-1818, 2012. DOI: http://doi.org/10.1111/j.1365-2621.2012.03036.x

JUAREZ, V.; NASCIMENTO, K. O.; SALDANHA, T.; BARBOSA, M. I. M. J.; JÚNIOR, J. L. B.. Composição química, aspectos microbiológicos e nutricionais de geleias de carambola e de hibisco orgânicas. Revista Verde de Agroecologia e Desenvolvimento Sustentável, Pombal, v.9, n.3, p.137-143, 2014.

KOGAN, R. D. M.; SASSANO, C. E. N.. Efeito do processamento térmico na composição centesimal do albedo in natura de maracujá amarelo (Passiflora edulis f. flavicarpa Degener) e da farinha de albedo produzida a $60 \circ \mathrm{C}$. Revista Educação, Guarulhos, v.8, n.2, 2013.

LAINETTI, A. M. S.. Elaboração de geleia de abacaxi com pimenta. Monografia (Bacharelado em Tecnologia de Alimentos) - Universidade Tecnológica Federal do Paraná, Curitiba, 2017.

LAYNE, E.. Spectrophotometric and turbidimetric methods of measuring proteins. In: COLOWICK, S. P.; KAPLAN, N. O.. Methods in enzymology. New York: Academic Press. 1957. p.447-454.

LEITE JÚNIOR, B. R. C.; OLIVEIRA, P. M.; CASTRO, R. L. E.; LAMAS, J. M. N.; MARTINS, E. M. F.. Desenvolvimento e caracterização de doce de goiaba cremoso adicionado de farinha de okara. Segurança Alimentar e Nutricional, Campinas, v.20, n.1, p.111-121, 2013. DOI: http://doi.org/10.5935/1809-2667.20130016

LEMKE, E. B.; MENEGAZZI, G. S.; RODRIGUES, R. S.; CHIM, J. F.; MACHADO, M. R. G.. Valorização do resíduo da beterraba (Beta vulgaris I.): avaliação das características físico-químicas de doce em massa. In: CONGRESSO BRASILEIRO DE CIÊNCIA E TECNOLOGIA DE ALIMENTOS, 25; CIGR SECTION IV INTERNACIONAL TECHNICAL SYMPOSIUM. FAURGS, 10. Anais. Gramado, 2016.

LICODIEDOFF, S.; AQUINO, A. D.; GODOY, R. C. B.; LEDO, C. A. S.. Avaliação da sinérese em geleia de abacaxi por meio de análise uni e multivariada. Semina: Ciências Exatas e Tecnológicas, Londrina, v.31, n.1, p.51-56, 2010.
LIMA, P. C.; SOUZA, B. S.; SANTINI, A. T.; OLIVEIRA, D. C. Aproveitamento agroindustrial de resíduos provenientes do abacaxi 'pérola' minimamente processado. Holos, Natal, v.2, p.122, 2017. DOI: http://doi.org/10.15628/holos.2017.5238

LOBO, M.G.; YAHIA, E.. Biology and Postharvest Physiology of Pineapple. John Wiley \& Sons Ltd., 2017.

MAMEDE, M. E. O.; DIB, C. L.; VIANA, E. S.; ALVES, O. L.; SOARES, F. W. S.; RITINGER, R.. Production of dietetic jam of umbu-caja (Spondias sp.): physical, physicochemical and sensorial evaluations. Food and Nutrition Sciences, v.4, p.461-468, 2013. DOI:

http://doi.org/10.4236/fns.2013.44059

MATSUURA, F. C. A. U.; FOLEGATTI, M. I. S.; MENEZES, H. C. Albedo de maracujá amarelo: propriedades físicas e funcionais. Campinas: Universidade Estadual de Campinas, 2005.

MIGUEL, A. C. A.; ALBERTINI, S.; BEGIATO, G. F.; DIAS, J. R. S.; SPOTO, M. H. F.. Aproveitamento agroindustrial de resíduos sólidos provenientes do melão minimamente processado. Ciência e Tecnologia de Alimentos, Campinas, v.28, p.733-737, 2008. DOI: http://doi.org/10.1590/S0101$\underline{20612008000300033}$

MONTEIRO, D. C. B.; SOUSA, W. C.; PIRES, C. R. F.; AZEVEDO, L. A.; BORGES, J. S.. Caracterização físico-química do fruto e da geleia de murici (Brysonima crassifólia). Enciclopédia Biosfera, Goiânia, v.11, n.21, 2015.

MORO, G. M. B.; RODRIGUES, R. S.; COSTA, J. A. V.; PIZATO, S.; MACHADO, W. R. C.. Avaliação da rotulagem e qualidade físico-química de geleias de uva comercializadas na cidade do Rio Grande/RS. Revista Brasileira de Tecnologia Agroindustrial, Ponta Grossa, v.7, n.1, p.897-910, 2013. DOI: http://doi.org/10.3895/S1981-36862013000100003

MOURA, A. G. C.; SOUSA, R. L. A.; OLIVEIRA, E. N. A.. Elaboração e caracterização físico-química e sensorial de casca de melão e albedo de maracujá cristalizados. Tecnologia e Ciência Agropecuária, João Pessoa, v.11, n.1, p.77-81, 2017.

OLIVEIRA, E. N. A.; ROCHA, A. P. T.; GOMES, J. P.; SANTOS, D. $C$.. Influência das variáveis de processo nas características físicas e químicas de geleias de umbu-cajá. Bioscience Journal, Uberlândia, v.30, n.6, p.1698-1710, 2014. DOI: http://doi.org/10.1590/1981-6723.09818

OLIVEIRA, L. F.; NASCIMENTO, M. R. F.; BORGES, S. V.; RIBEIRO, P. C. N.; RUBACK, V. R.. Aproveitamento alternativo da casca do maracujá amarelo (Passiflora edulis F.

flavicarpa) para produção de doce em calda. Ciência e Tecnologia de Alimentos, Campinas, v.22, n.3, p.259-262, 2002. DOI: http://doi.org/10.1590/S010120612002000300011

ORSI, D. C.; NISHI, A. C. F.; CARVALHO, V. S.; ASQUIERI, E. R.. Caracterização química, atividade antioxidante e formulação de doces com feijão azuki (Vigna angularis). Brazilian Journal of Food Technology, Campinas, v.20, n.e2016174, p.1-6, 2017. DOI: http://doi.org/10.1590/1981-6723.17416 
PEDREIRA, A. C. C. P.; NAVES, R. V.; NASCIMENTO, J. L.. Variação sazonal da qualidade do abacaxi cv. Pérola em Goiânia, estado de Goiás. Pesquisa Agropecuária Tropical, Goiânia, v.38, p.262-268, 2008.

PEREIRA, M. A. B.; SIEBENEICHLER, S. C.; LORENÇONI, R.; ADORIAM, G. C.; SILVA, J. C.; GARCIA, R. B. M.; PEQUENO, D. N. L.; SOUZA, C. M.; BRITO, R. F. F.. Qualidade do fruto de abacaxi comercializado pela Cooperfruto - Miranorte - TO. Revista Brasileira de Fruticultura, Jaboticabal, v.31, p.10481053, 2009. DOI: http://doi.org/10.1590/S0100$\underline{29452009000400018}$

POLESI, L. F.; MATTA JUNIOR, M. D.; MATSUOKA, C. R.; CEBALLOS, C. H. M.; ANJOS, C. B. P.; SPOTO, M. H. F.; SARMENTO, S. B. S.. Caracterização física e química de geleia de manga de baixo valor calórico. Revista Brasileira de Produtos Agroindustriais, Campina Grande, v.13, n.1, p.8590, 2011. DOI: http://dx.doi.org/10.15871/15178595/rbpa.v13n1p85-90

QUERIDO, A. F.; SILVA, C. S. A.; GUIMARÃES, D. H. P.; ALVES, G. L.. Persimmon pulp and jelly: chemical characterization and rheological behavior. Brazilian Journal of Applied Technology for Agricultural Science, Guarapuava, v.6, n.2, p.97-103, 2013.

REZENDE, F. A.; GROFF, A. M.. Análise da composição química da casca do maracujá azedo e suas principais características físicas. In: CONGRESSO CIENTÍFICO DA REGIÃO CENTRO-OCIDENTAL DO PARANÁ. Anais. Campo Mourão: Centro Universitário Integrado de Campo Mourão, 2016.

ROSA, N. C.; TRINTIM, L. T. CORRÊA, R. C. G.; VIEIRA, A. M. S. V.; BERGAMASCO, R.. Elaboração de Geleia de abacaxi com hortelã zero açúcar: processamento, parâmetros físicoquímicos e análise sensorial. Revista Tecnológica, Curitiba, p.83- 89, 2011. DOI:

http://doi.org/10.4025/revtecnol.v0i0.14994

SANTANA, D.C. N.; ALVEZ, A. M. A.; SANTOS, A. F.; BEZERRA, J. M.; ARAUJO, J. F. S.. Qualidade de doce em massa de banana adicionado de componentes funcionais. Caderno Verde de Agroecologia e Desenvolvimento Sustentável, Pombal, v.4, n.1, 2014.

SANTOS, C. X.. Caracterização Físico-química e Análise da Composição Química da Semente de Goiaba Oriunda de Resíduos Agroindustriais. Dissertação (Mestrado em Engenharia de Alimentos) - Universidade Estadual do Sudoeste da Bahia, Itapetinga, 2011.

SANTOS, P. R. G.; CARDOSO, L. M.; BEDETTI, S. F.; HAMACEK, F. R.; MOREIRA, A. V. B.; MARTINO, H. S. D.; PINHEIROSANT'ANA, H. M.. Geleia de Cagaita (Eugenia dysenterica DC.): desenvolvimento, caracterização microbiológica, sensorial, química e estudo da estabilidade. Revista Instituto Adolfo Lutz, São Paulo, v.71, p.281-290, 2012.

SANTOS, S. A.. Efeito do tempo na composição físicoquímica, química e na atividade da bromelina do caule do abacaxizeiro Ananas comosus (L.) Merr. CV. Pérola armazenado em condições com e sem refrigeração. Dissertação (Mestrado em Ciência dos Alimentos) Universidade Federal de Lavras, Lavras, 1995.
SANTOS, T. S.. Determinação de macronutrientes em polpas in natura e industrializada de abacaxi (Ananas Comosus $\mathrm{L}$. Merril), comercializadas em São Luís/MA. Monografia (Bacharela em Química Industrial) - Universidade Federal do Maranhão, São Luíz, 2017.

SAS INSTITUTE. SAS for Windows, versão 9.4 SAS ${ }^{\circledR}$ : SAS User guide. Carry, 2013.

SCOLFORO, C. Z.; SILVA, E. M. M.. Elaboração de Geleia de maçã com frutooligossacarídeo. Revista Alimentos e Nutrição, Araraquara, v.24, n.1, p.115-125, 2013.

SILVA, F. T.. Manual de produção artesanal de doce em massa. Rio de Janeiro: EMBRAPA, 1997.

SILVA, T. L. L.; BECKER, F. S.; TOGUCHI, M. Y.; VILAS BOAS, E. V. B.; DAMIANI, C.. Aplicabilidade tecnológica da marmelada-de-cachorro (Alibertia sessilis Schum.). Revista Brasileira de Produtos Agroindustriais, Campina Grande, v.15, n.3, p.263-271, 2013. DOI: http://doi.org/10.15871/1517-8595/rbpa.v15n3p263-271

SINGH, S.; JAIN, S.; SINGH, S. P.; SINGH, D.. Quality changes in fruit jams from combinations of different fruit pulps. Journal of Food Processing and Preservation, Hoboken, v.33, p.41-47, 2009. DOI: http://doi.org/10.1111/j.17454549.2008.00249.x

SOARES, L. M. V.; SHISHIDO, K.; MORAES, A. M. M.; MOREIRA, V. A.. Composição mineral de sucos concentrados de frutas brasileiras. Ciência e Tecnologia de Alimentos, Campinas, v.24, n.2, p.202-206, 2004. DOI: http://doi.org/10.1590/S0101-20612004000200007

SOUTO, R. F.; DURIGAN, J. F.; SOUZA, B. S.; DONADON, J.; MENEGUCCI, J. L. P.. Conservação pós-colheita de abacaxi 'Pérola' colhido no estádio de maturação 'pintado' associando-se refrigeração e atmosfera modificada. Revista Brasileira de Fruticultura, Jaboticabal, v.26, p.24-28, 2004. DOI: http://doi.org/10.1590/S0100-29452004000100008

TACO. Tabela Brasileira de Composição de Alimentos. 4 ed. Campinas: NEPA, 2011.

THÉ, P. M. P.; NUNES, R. P.; SILVA, L. I. M. M.; ARAÚJO, B. M.. Características físicas, físico-químicas, químicas e atividade enzimática de abacaxi Cv Smoth Cayene recémcolhido. Revista Alimentos e Nutrição, Araraquara, v.21, n.2, p.273-281, 2010.

USP. Universidade de São Paulo. Tabela brasileira de composição de alimentos (TBCA-USP 5.0). São Paulo: USP, 2008.

VENTURA, J. A.; COSTA, H.; CABRAL, J. R. S.; MATOS, A. P.. Vitória: new pineapple cultivar resistent to fusariosis. Acta Horticulturae, The Hague, v.822, p.51-56, 2009. DOI: http://doi.org/10.17660/ActaHortic.2009.822.4

VICENTE, J.; NASCIMENTO, K. O.; SALDANHA, T.; BARBOSA, M. I. M. J.; JÚNIOR, J. L. B.. Composição química, aspectos microbiológicos e nutricionais de geleias de carambola e de hibisco orgânicas. Revista Verde de Agroecologia e 
Desenvolvimento Sustentável, Pombal, v.9, n.3, p.137-143, 2014.

XAVIER, G. F.; SOUZA, B. S.; CÂNDIDO, T. A. T.. Determinação da composição centesimal da casca e da farinha da casca de maracujá. In: JORNADA CIENTÍFICA E TECNOLÓGICA DO IFSULDEMINAS, 7; SIMPÓSIO DE PÓS-GRADUAÇÃO, 4. Anais. Poços de Caldas, 2015.
YUYAMA, K.; MENDES, N. B.; VALENTE, J. P.. Longevidade de sementes de camu-camu submetidas a diferentes ambientes e formas de conservação. Revista Brasileira de Fruticultura, Jaboticabal, v.33, n.2, p.601-607, 2011. DOI: http://doi.org/10.1590/S0100-29452011005000067

A CBPC - Companhia Brasileira de Produção Científica (CNPJ: 11.221.422/0001-03) detém os direitos materiais desta publicação. Os direitos referem-se à publicação do trabalho em qualquer parte do mundo, incluindo os direitos às renovações, expansões e disseminações da contribuição, bem como outros direitos subsidiários. Todos os trabalhos publicados eletronicamente poderão posteriormente ser publicados em coletâneas impressas sob coordenação da Sustenere Publishing, da Companhia Brasileira de Produção Científica e seus parceiros autorizados. Os (as) autores (as)

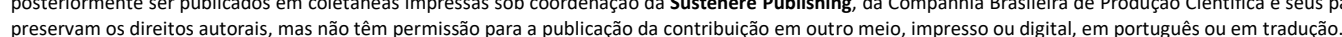

